\title{
DEVELOPMENT OF A TOMATO/ROOT KNOT NEMATODE BIOASSAY TO SCREEN BENEFICIAL MICROBES
}

\author{
L.T. AALDERS ${ }^{1}$, R. MINCHIN ${ }^{2}$, R.A. HILL ${ }^{2}$, M. BRAITHWAITE ${ }^{2}$, \\ N.L. BELL ${ }^{1}$ and A. STEWART ${ }^{2}$ \\ ${ }^{\text {I} A g R e s e a r c h, ~ R u a k u r a ~ R e s e a r c h ~ C e n t r e, ~ P r i v a t e ~ B a g ~ 3123, ~ H a m i l t o n, ~}$ \\ New Zealand \\ ${ }^{2}$ Bio-Protection Research Centre, P.O. Box 84, Lincoln University, Lincoln 7647, \\ New Zealand
}

Corresponding author:lee.aalders@agresearch.co.nz

\begin{abstract}
In common with other root knot nematodes Meloidogyne hapla is a serious plant pest. A rapid screening system for candidate microbes that benefit plant growth is a first step to developing screening bioassays in other plant-nematode systems. Cultures of M. hapla established on tomatoes were used to define the nematode damage function, and required bioassay duration for this plant-pest system, followed by scale-up to a glasshouse level. The quantities of Meloidogyne inoculum were chosen such that they would cause minor, moderate or severe plant damage; hence the degree of protection afforded by the microbes in bioassays could be readily evaluated. An inoculation rate of $3542 \mathrm{eggs} / \mathrm{plant}$ caused a significant reduction in shoot weight $(30 \%)$ and an increase in root galling in excess of $50 \%$. Percentage of root gall and root gall index were good indicators of nematode impact and provide a relatively quick method of assessment. Keywords: Meloidogyne hapla, Lycopersicon esculentum, bioassay, root gall index.
\end{abstract}

\section{INTRODUCTION}

Bioassay systems need to be relatively cheap, efficient and repeatable to allow for rapid screening of beneficial bio-nematicidal and growth promoting microbes. For this study a tomato/nematode (Lycopersicon esculentum/Meloidogyne hapla) system was chosen because tomato is a high value crop that is widely grown around the world. Approximately 1.2 billion tonnes of tomatoes are produced worldwide annually (Anonymous 2006), of which nematodes are estimated to cause $20 \%$ yield loss (Barker 1998) costing at least $\$ 37 \mathrm{M}$ in nematicide use alone (Nematech 2007). The root-knot nematode $M$. hapla is one of the nematode pests of tomato, but also infects a wide range of other economically important plants (Carter 1985; Knight et al. 1997) and has a wide distribution particularly in temperate areas of the world (Jepson 1987; Anonymous 2002). Other benefits of choosing this plant/nematode system include: the potential to export biocontrol agents to other tomato growing countries; symptoms of infection develop fast and are easily observed and able to be assessed; and the level of disease severity can be simply manipulated by modifying nematode inoculation rates.

Meloidogyne hapla causes root galling in susceptible host plants. The infection cycle begins with the first-stage juvenile, which moults while still within the egg. The second stage infective juvenile (J2) hatches and enters the root of a susceptible host plant, forming an attachment site. The nematode then becomes sedentary. A root gall forms around the nematode in response to feeding and the nematode swells and undergoes several moults before becoming a saccate adult female, which produces a gelatinous mass of eggs (Eisenback \& Triantaphyllou 1991). 
The experiments reported here were designed to quantify the $M$. hapla damage function on tomatoes at $20^{\circ} \mathrm{C}$, minimise bioassay duration to increase throughput, and to scale-up the bioassay for use in glasshouse testing.

\section{MATERIALS AND METHODS}

Meloidogyne hapla stock populations were maintained in the glasshouse on tomato plants (cv. 'Rutgers') in a potting mix:sand (sieved $6 \mathrm{~mm})(50: 50$ by weight) growing medium with Osmocote ${ }^{\circledR}$ as a fertiliser source.

Meloidogyne hapla egg masses from galled tomato roots were excised, washed and placed in a 1 litre Schott bottle. Nematode eggs were separated from the egg mass with $0.5 \% \mathrm{NaOCl}$ solution (Hussey \& Barker 1973). The resulting inoculum was washed through nested $150 \mu \mathrm{m}$ and $20 \mu \mathrm{m}$ sieves, the first to remove root debris and the latter to collect the nematode eggs and juveniles (a $38 \mu \mathrm{m}$ sieve was included in the glasshouse experiment to remove $\mathrm{J} 2 \mathrm{~s}$ ). The inoculum collected on the $20 \mu \mathrm{m}$ sieve was then washed into a beaker. Subsamples $(1 \mathrm{ml})$ were taken and counted on a Doncaster dish to estimate egg and juvenile numbers.

In all experiments, two tomato seeds (cv. 'Money Maker') were sown at a depth of $6 \mathrm{~mm}$. Seedlings were thinned before nematode inoculation leaving one seedling per replicate. All bioassays were overhead watered as required. The damage function and duration bioassays were carried out in a controlled environment $(\mathrm{CE})$ room at $20^{\circ} \mathrm{C}$ with 16:8 h light:dark, using individual root trainers that contained $100 \mathrm{~g}$ growing medium (as described above). The drainage holes at the base of the trainers were plugged with an absorbent cotton ball to prevent soil escaping. In the glasshouse bioassay, carried out at ambient temperatures ranging between $20-35^{\circ} \mathrm{C}$, plants were grown in $\mathrm{PB} 3 / 4$ planter bags (500 g growing medium). .

Tomato seedlings were inoculated with nematodes at tomato seedling emergence, which equated to 7 days after seeds were sown for the damage function and duration experiments and 9 days for the glasshouse experiment. A randomised block design was used for the damage function and duration experiments and a complete randomised design for the glasshouse experiment.

\section{Nematode damage function experiment - controlled environment}

A dilution series $(0,200,370,870,1700,3080,6700$ and 13880/2 ml) of M. hapla eggs was made by addition of distilled water. Each dilution was added to a separate trainer as a $1 \mathrm{ml}$ aliquot to each of two holes approximately $1 \mathrm{~cm}$ from the seedling on either side to a depth of $2 \mathrm{~cm}$. All dilution rates were replicated nine times.

Plants were assessed 28 days post nematode inoculation. Shoot and root weights were measured by drying for $48 \mathrm{~h}$ at $80^{\circ} \mathrm{C}$ and roots were scored visually for the proportion of galling as a percentage of the total root mass. The relationship between tomato shoot weight and initial nematode inoculum density was described by the Seinhorst equation, where relative yield is described by $\mathrm{y}=\mathrm{m}+(1-\mathrm{m}) \mathrm{z}^{(\mathrm{P}-\mathrm{T})}$; where $\mathrm{m}$ is the minimum yield, $\mathrm{Z}$ a constant reflecting nematode damage, $\mathrm{P}$ the initial population density and $\mathrm{T}$ the tolerance limit below which no yield reduction occurs. Parameters of the Seinhorst equation were calculated using YerCurve, a computer program for MSDOS (http:// nematode.unl.edu/SOFTWARE/nemasoft.htm), which is based on the SeinFit program (Viaene et al. 1997).

\section{Bioassay duration experiment - controlled environment}

Four rates of $M$. hapla eggs (plus juveniles) were applied: 0; 2000 (plus $60 \mathrm{~J} 2 \mathrm{~s}$ ); 2940 (plus 84 J2s); and 4028 (plus 112 J2s). These rates were added as a 1 ml aliquot per root trainer into a single hole made approximately $1 \mathrm{~cm}$ from the seedling to a depth of $2 \mathrm{~cm}$. There were 10 replicates for each rate.

Plants were assessed 19 days post nematode inoculation. Shoot and root fresh weights was recorded, as was shoot dry weight, and roots were scored for degree of galling as a percentage of the total root mass. 


\section{Scale-up glasshouse experiment}

Six rates of $M$. hapla eggs were inoculated (0, 200, 370, 870, 1700 and 3100 eggs/2 ml) at seedling emergence as two $1 \mathrm{ml}$ aliquots to each planter bag via holes $1 \mathrm{~cm}$ away from the seedling and to a depth of $2 \mathrm{~cm}$. Each rate was replicated five times. Fifty days after nematode inoculation, shoot and root weights were measured by drying at $65^{\circ} \mathrm{C} \mathrm{for}$ 2 days. Root galling was scored using a root gall index (Bridge \& Page 1980). This root gall index rates severity of galling on a $0-10$ scale, with 10 being most severe.

\section{Statistical analysis}

Data from the damage function experiment were analysed by ANOVA using untransformed data for all parameters except percent root gall data, which were angularly transformed. Data from the glasshouse experiment were analysed using ANOVA. Means were separated using Fisher's Protected LSD (95\% confidence).

\section{RESULTS}

For the damage function experiment, there was a significant reduction in shoot dry weight of tomato seedlings inoculated with 3080 (0.581 g/plant), 6700 (0.447 g/plant) and $13880(0.319 \mathrm{~g} / \mathrm{plant}) M$. hapla eggs when compared to the control (mean $=0.846$ $\mathrm{g} /$ plant $)(\mathrm{P}<0.001, \mathrm{SED}=0.100)$. The Seinhorst equation (using $\mathrm{m}=0.270, \mathrm{z}=0.9995$ and $\mathrm{T}=1568)$ calculated that moderate shoot yield reduction $(70 \%$ of maximum yield $)$ would occur with a M. hapla egg inoculation rate of 3542 eggs and that severe yield reduction (50\% of maximum) would occur at an inoculation rate of 7668 eggs (Fig. 1). Root dry weights were not significantly different between the control and any of the nematode inoculation rates. There was a significant increase $(\mathrm{P}<0.001)$ in the percentage of root mass galled as the M. hapla inoculum rate increased (no galling at 0 eggs), with $50 \%$ of the root mass galled at the 3080 M. hapla rate (Figs $2 \& 3$ ).

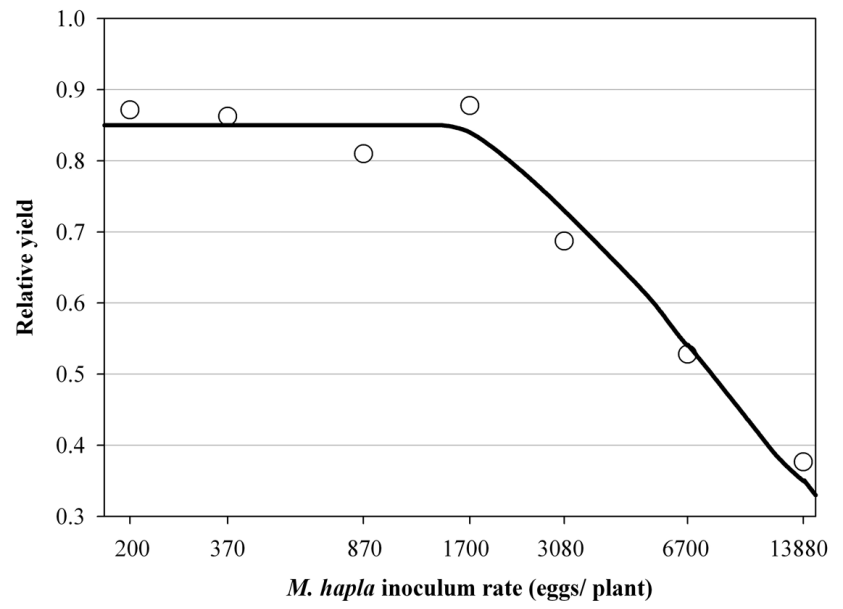

FIGURE 1: The relationship between Meloidogyne hapla egg inoculum rate (drawn on a natural log scale) and relative tomato shoot yield, at $20^{\circ} \mathrm{C}$ after 28 days incubation in the nematode damage function experiment. A Seinhorst damage function curve is fitted to the data (see text for details).

For the duration experiment, there was a significant increase in root galling from 15 to $31 \%$ as the inoculum increased (Table 1), which was lower than observed in the damage function experiment, particularly for rates above 3000 nematodes/plant. There was, however, no significant effect on shoot or root weight at any of the inoculum levels. 
TABLE 1: Tomato root galling (\%), shoot and root fresh weight and shoot dry weight (g/plant) under various Meloidogyne hapla egg inoculum rates in a controlled environment room $\left(20^{\circ} \mathrm{C}\right)$ for the duration experiment. Values after angular transformation are given in parentheses.

\begin{tabular}{lcccccc}
\hline & \multicolumn{7}{c}{ Inoculation rate (nematodes/plant) } & & \\
\cline { 2 - 5 } Parameter & 0 & 2060 & 3024 & 4140 & LSD & P-value \\
\hline Gall (\%) & $0(0)$ & $15(0.395)$ & $22.8(0.491)$ & $31.1(0.586)$ & $(0.073)$ & $<0.001$ \\
Shoot dry weight & 0.138 & 0.141 & 0.142 & 0.130 & 0.053 & 0.986 \\
Shoot fresh weight & 1.453 & 1.445 & 1.506 & 1.348 & 0.513 & 0.951 \\
Root fresh weight & 0.232 & 0.327 & 0.354 & 0.344 & 0.115 & 0.105 \\
Root:shoot & 0.147 & 0.215 & 0.237 & 0.254 & 0.034 & $<0.001$ \\
\hline
\end{tabular}

In the glasshouse experiment a significant increase in the root gall index (RGI) relative to the untreated control was observed for all inoculum rates $(200,370,870,1700$ and 3100 eggs/plant) (Table 2). A plateau in RGI was reached at the highest nematode inoculation rates of 1700 and 3100 eggs/plant respectively (Table 2). There were no significant differences relative to the control, in either root or shoot dry weights, at any of the nematode egg inoculation rates (Table 2).

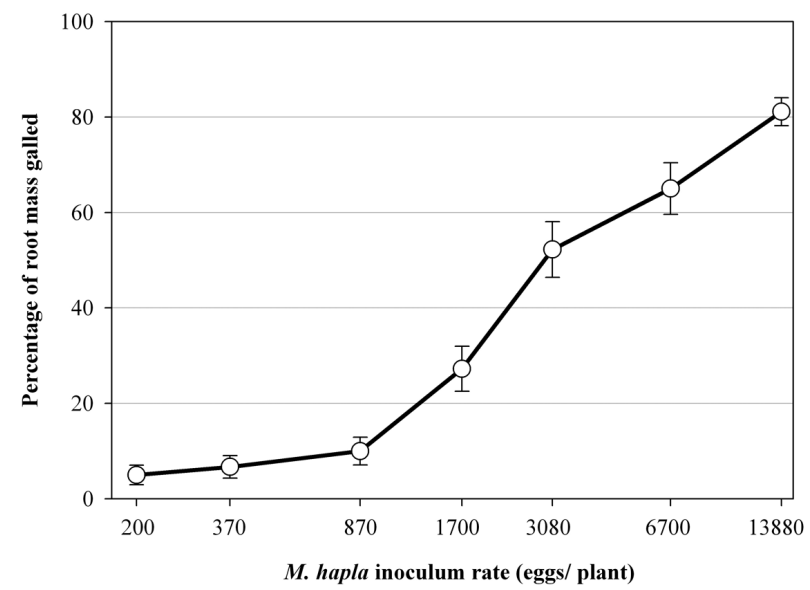

FIGURE 2: Tomato root galling (\% of root mass galled) in relation to Meloidogyne hapla egg inoculum rates (drawn on a log scale) at $20^{\circ} \mathrm{C}$ after 19 days incubation in the duration experiment. Error bars are SEM.

TABLE 2: Tomato root gall index (RGI) along with shoot and root dry weights (g/plant) under various Meloidogyne hapla egg inoculum rates in the glasshouse bioassay.

\begin{tabular}{lllllllll}
\hline & \multicolumn{7}{c}{ Inoculation rate (nematodes/plant) } & \\
\cline { 2 - 7 } Parameter & 0 & 200 & 370 & 870 & 1700 & 3100 & LSD & P-value \\
\hline Root gall index & 0 & 1 & 1.2 & 2.25 & 3.6 & 3.8 & 0.514 & $<0.001$ \\
Shoot dry weight & 2.80 & 2.67 & 2.72 & 2.85 & 3.00 & 3.33 & 0.670 & 0.381 \\
Root dry weight & 0.36 & 0.39 & 0.36 & 0.45 & 0.39 & 0.36 & 0.151 & 0.830 \\
Root:shoot & 0.13 & 0.14 & 0.13 & 0.16 & 0.13 & 0.11 & 0.052 & 0.554 \\
\hline
\end{tabular}




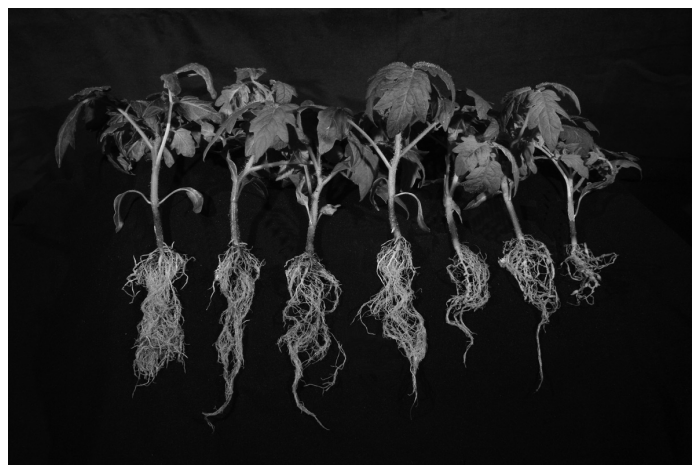

FIGURE 3: Tomato seedlings from Replicate 1 at harvest (28 days post Meloidogyne hapla inoculation) in the nematode damage function experiment. Left to right: inoculation rate of $0,200,370,1700,3080,6700$ and 13880 M. hapla eggs.

\section{DISCUSSION}

Results from the damage function experiment showed that 3542 eggs/plant gave a reduction (ca 30\%) in shoot dry weight and an increase in root galling. A similar shoot weight reduction was observed by Olthof \& Potter (1977) at 18 weeks after single 6-week-old tomato seedlings were transplanted into microplots infested with 2795 larvae/100 g of soil. This reduction in weight resulted in fruit yield losses of 40\%. Stephan (1983) found that in two out of the three populations examined, a $30 \%$ or greater reduction in tomato shoot weight was recorded after 60 days when 3-week-old seedlings were transplanted into pots with initial densities of $4000 \mathrm{eggs} / 500 \mathrm{~g}$ soil; with the third population, approximately $30 \%$ reduction in top weight occurred at 8000 eggs $/ 500 \mathrm{~g}$. Barker et al. (1976) found initial numbers of 1000 or more larvae and eggs in microplots (four 5 -week-old transplanted seedlings/microplot) gave significant reductions in fruit yield of approximately $20 \%$.

Root galling, expressed either as a percentage of the total root mass or as an index, was the best parameter for measuring nematode infection in both the duration and glasshouse experiments. However, neither of these experiments showed any significant difference in shoot weight between the nematode treated and the untreated control. This result may be due to the duration of each experiment, with 19 days being too short for differences to occur in the duration experiment. In the glasshouse experiment 50 days may have allowed the partial recovery of plants before the invasion of a second generation of nematodes or before the second generation had a detrimental effect on plant growth. Alternatively, for the glasshouse bioassay it is possible that the roots of the tomato plants had a larger space to utilise and thus grew away from the site of M. hapla inoculation.

Root dry weights were unaffected by nematode levels and were not a good indicator of nematode damage. No significant differences compared to the controls were detected in any of the three experiments. This was also the conclusion of Talavera et al. (2001), where the authors concluded that the presence of galling could in fact increase the relative dry weights of roots compared to the control.

These bioassays successfully established inoculum levels and assessment criteria, which can be used in the screening of potential biocontrol agents for M. hapla on tomato seedlings and will be used for this purpose in future experiments. Shoot dry weight assessed at 28 days, percent root galling or the root gall index were good indicators of nematode effect and allowed a relatively quick method of disease assessment. The damage function and duration experiments conducted under controlled environmental conditions 
enabled an efficient and repeatable system, which will be useful as an initial step for screening beneficial bio-nematicidal and growth promoting microbes. The upscaling to a glasshouse situation is the next step closer to a more natural cropping situation with plants and nematodes exposed to variation in light and temperature. Additionally, this tomato/ nematode system could be relatively easily modified for use on other plant/nematode systems for both disease assessment and the screening of beneficial microbes.

\section{ACKNOWLEDGEMENTS}

The authors thank Chelve Rohan for technical assistance and Neil Cox for statistical analysis. The research was funded by the Foundation for Research, Science and Technology Contract C10X0706.

\section{REFERENCES}

Anonymous 2002. Meloidogyne hapla. [Distribution map]. In: Distribution Maps of Plant Diseases. Edition 1. Map No. 853.

Anonymous 2006. Faostat. http://faostat.fao.org/ (accessed 27 March 2009).

Barker KR 1998. Introduction and synopsis of advancements in nematology. In: Barker KR, Pederson GA, Windham GL ed. Plant nematode interactions. American Society of Agronomy Inc., Crop Science Society of America Inc., Soil Science Society of America Inc., Madison. Pp. 1-20.

Barker KR, Shoemaker PB, Nelson LA 1976. Relationships of initial population densities of Meloidogyne incognita and M. hapla to yield of tomato. Journal of Nematology 8: 232-239.

Bridge J, Page SLJ 1980. Estimation of root-knot nematode infestation levels on roots using a rating chart. Tropical Pest Management 26: 296 - 298.

Carter CC 1985. Literature search: host range of Meloidogyne hapla. International Nematology Network Newsletter 2: 16-24.

Eisenback JD, Triantaphyllou HH 1991. Root-knot nematodes: Meloidogyne species and races. In: Nickle WR ed. Manual of Agricultural Nematology. Pp. 191-274.

Hussey RS, Barker KR 1973. A comparison of methods of collecting inocula of Meloidogyne sp., including a new technique. Plant Disease Reporter 57: 10251028.

Jepson SB 1987. Identification of root-knot nematodes (Meloidogyne species). CAB International, Wallingford, UK. 265 p.

Knight KWL, Barber CJ, Page GD 1997. Plant-parasitic nematodes of New Zealand recorded by host association. Journal of Nematology 29: 640-656.

Nematech 2007. Estimated \% loses due to nematodes. Centre for Plant Sciences, University of Leeds, UK. http://www.biology.leeds.ac.uk/nem/nematech/biosafety/ biosafety.htm (accessed 27 March 2009).

Olthof THA, Potter JW 1977. Effects of population densities of Meloidogyne hapla on growth and yield of tomato. Journal of Nematology 9: 296-300.

Stephan ZA 1983. The effect of different densities of Meloidogyne ardenensis and of three populations of $M$. hapla on the growth of tomato at four soil temperatures. Nematologia Mediterranea 11: 93-100.

Talavera M, Itou K, Mizukubo T 2001. Reduction of nematode damage by root colonization with arbuscular mycorrhiza (Glomus spp.) in tomato-Meloidogyne incognita (Tylenchida : Meloidognidae) and carrot-Pratylenchus penetrans (Tylenchida : Pratylenchidae) pathosystems. Applied Entomology and Zoology 36: 387-392.

Viaene NM, Simoens P, Abawi GS 1997. SeinFit, a computer program for the estimation of the Seinhorst equation. Journal of Nematology 29: 474-477. 